\title{
Experimental production of gastric epithelium in the duodenum
}

\author{
J. RHODES \\ From the Medical Unit, Cardiff Royal Infirmary, Wales
}

EDITORIAL SYNOPSIS The findings in this experimental study in cats resemble those previously noted in man with hypersecretion of acid by the stomach. The gastric type epithelium which develops in the duodenum probably arises from the necks of Brunner's glands.

Intestinal metaplasia is a well-known occurrence in the human stomach. James (1963) has recently described the reverse anomaly, gastric epithelium in the duodenum. He examined biopsies taken at operation from the first part of the duodenum: patches of gastric epithelium were commonly found in patients with duodenal ulcer but were rare in patients with gastric ulcer or carcinoma. One patient with the Zollinger-Ellison syndrome had extensive gastric epithelium in the second part of the duodenum. Another patient who had an increased gastric acid secretion also had the change in the second part of the duodenum (James, 1963).

These findings suggested a possible association between gastric epithelium in the duodenum and a high gastric acid secretion. This paper describes experiments to test whether the unusually high secretion of acid promoted by repeated injections of histamine could cause gastric epithelium to develop in the duodenal mucosa.

\section{METHODS}

Adult cats, 12 females and eight males, were given intramuscular injections of histamine suspended in beeswax. In an attempt to find a suitable dosage of histamine, animals were given different doses for varying periods, the longest of which was four weeks. Some experiments had to be stopped because the animals became ill. Seven cats, which were not given histamine, served as controls. Al! the cats were killed by intrathoracic nembutal 24 hours after their last injection.

Histamine was suspended in beeswax by the method described by Hay, Varco, Code, and Wangensteen (1942) and was diluted with mineral oil to give concentrations of 2,10 , and $20 \mathrm{mg} . / \mathrm{ml}$. The injection, which was given at 9.00 a.m. each day, could then be given without warming the preparation. By giving histamine suspended in beeswax to dogs with Heidenhain pouches it was shown that the effect of a single injection lasted for 24 to 36 hours.
Immediately after death, the stomach and upper small intestine were removed, and a note was made of any mucosal ulceration or reddening. The entire duodenum with some antrum and jejunum was rolled up and fixed in $10 \%$ formol saline for $\mathbf{4 8}$ hours. The preparation was then cut longitudinally in two places, and sections were taken from the three pieces of tissue so obtained. They were stained by haematoxylin and eosin, and by periodic acid-Schiff reagent (P.A.S.). Suitably fixed tissue was not obtained from two female and two male cats.

Three sections from each animal were examined for ulceration and stunting or flattening of the villi. Particular attention was paid to the nature of the surface epithelium and the presence of mucus-containing cells resembling gastric cells. The number of patches of gastric epithelium was counted but no attempt was made to count individual cells. The location of the patches was recorded. Because the transition from gastric to duodenal epithelium at the pylorus was often not sharp, no attention was paid to the first $0.2 \mathrm{~cm}$. of the duodenum.

\section{RESULTS}

MACROSCOPIC CHANGES The control cats showed no abnormality of the stomach or duodenum. Mucosal damage often developed in the cats injected with histamine (Table I). Of the 20 injected cats, six had duodenal ulcers, one had both a duodenal and a gastric ulcer, five had gastric ulcers, of which three had duodenal reddening, and a further three had duodenal reddening only. Five of the treated cats showed no abnormality.

The development of ulceration and its incidence depended on the dose of histamine. Of the five cats given $0.5 \mathrm{mg}$. per $\mathrm{kg}$. of body weight, four had no abnormality and one had duodenal reddening only. Of the $\mathbf{1 5}$ cats given more than this dose, only one had no abnormality, 11 had ulcers, and two had duodenal reddening. 
TABLE I

HISTAMINE ADMINISTRATION AND MACROSCOPIC APPEARANCES

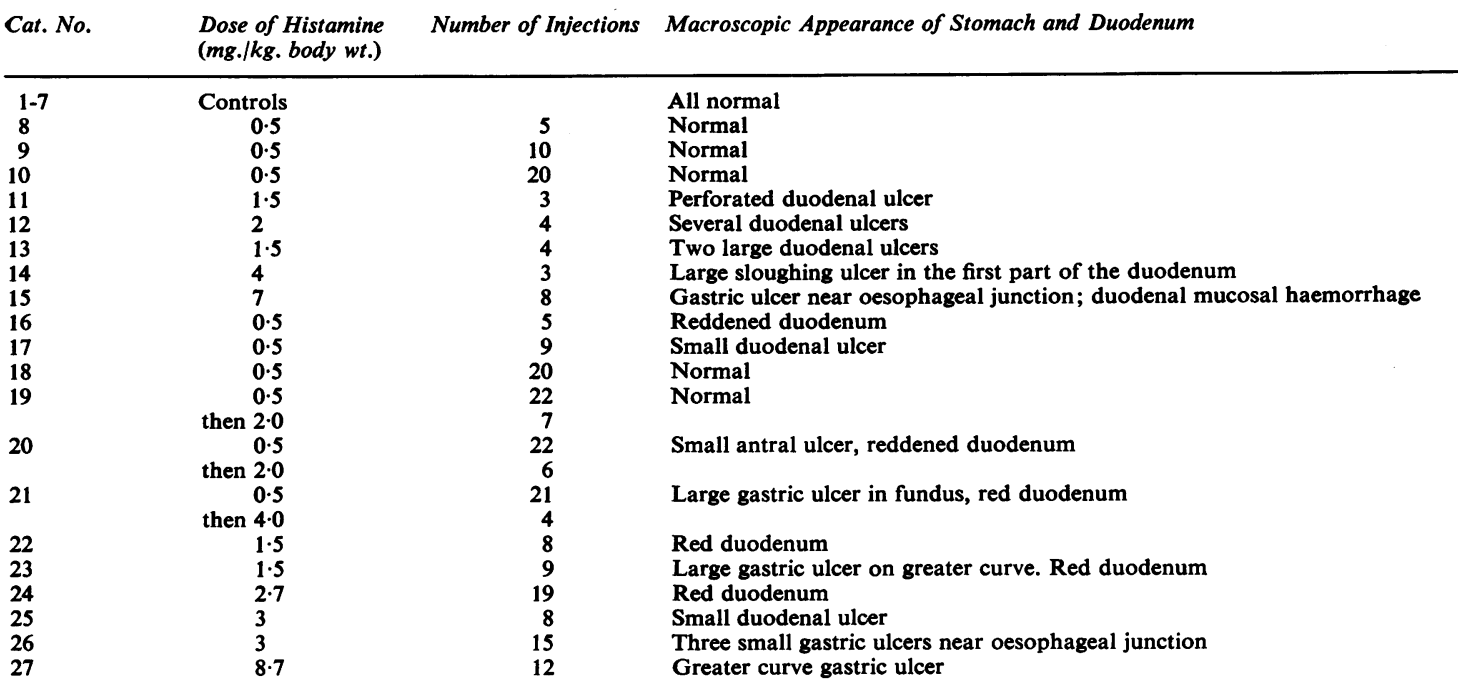

Duodenal ulceration was commoner and developed sooner in males than in females when both were given histamine in the same dosage. All the five males given more than $0.5 \mathrm{mg}$. per $\mathrm{kg}$. of histamine had severe duodenal ulceration. Of the nine females given similar doses only six developed ulcers, of which four were gastric and two duodenal.

This difference in susceptibility between the sexes is reflected in the number of injections given. The experiments in which male cats developed ulcers had to be stopped within eight days, whereas in the female group some of the experiments were continued for three or four weeks.

MICROSCOPIC ULCERATION Microscopic ulceration of the mucosa did not occur in any of the controls but was present in eight of the 16 injected animals. These eight included all the five which had macroscopic duodenal ulceration, two with duodenal reddening and one with a gastric ulcer. The ulcers usually occurred in areas which were flat and devoid of villi.

VILLOUS SIZE All the control cats had normal-sized villi except one in which the villi were stunted.

All the eight injected cats without mucosal ulceration had normal villi. In those eight with ulceration seven had some areas of stunted or flattened villi. (Table II.)

GASTRIC EPITHELIUM Patches of gastric epithelium were seen on some of the duodenal villi in some cats. These patches were easily distinguishable with P.A.S. stain; the cells composing them contained a mucous droplet near the surface, and had no brush border. Examples of such patches are shown in Figures 1, 2, and 3. They were more common in cats injected with histamine than in control cats. Ten out of 16 of the injected cats had such patches compared with one out of seven controls (Table II).

TABLE II

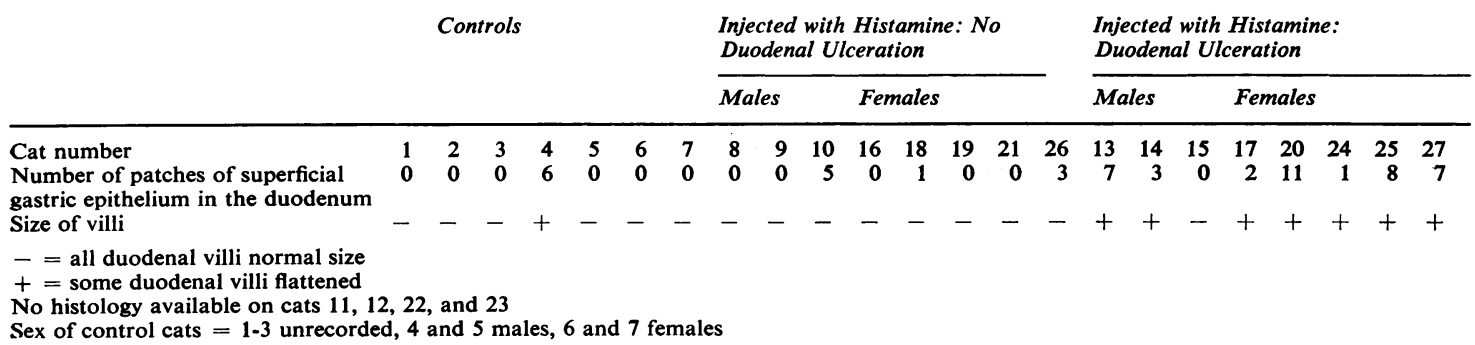



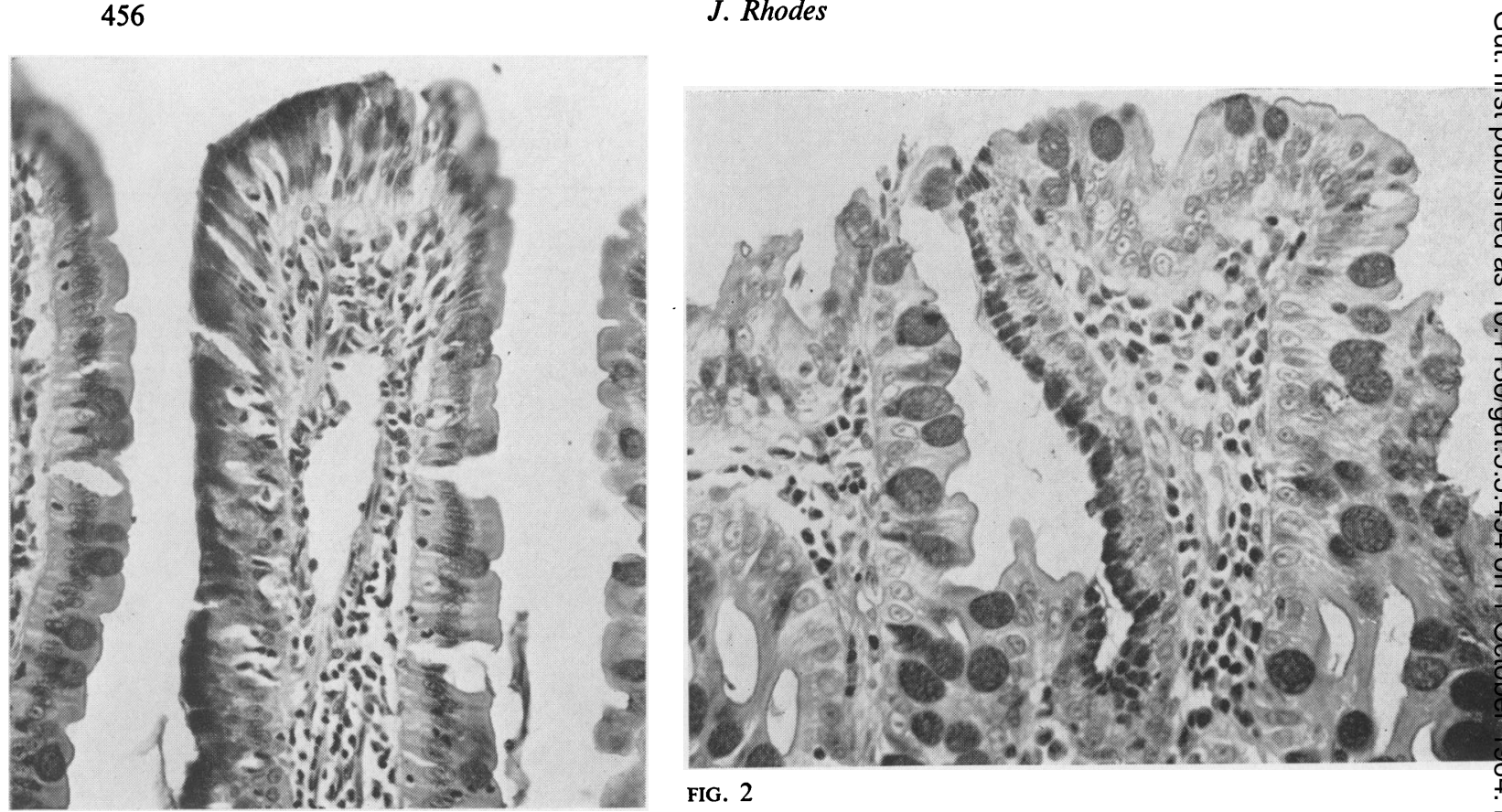

FIG. 2

FIG. 1

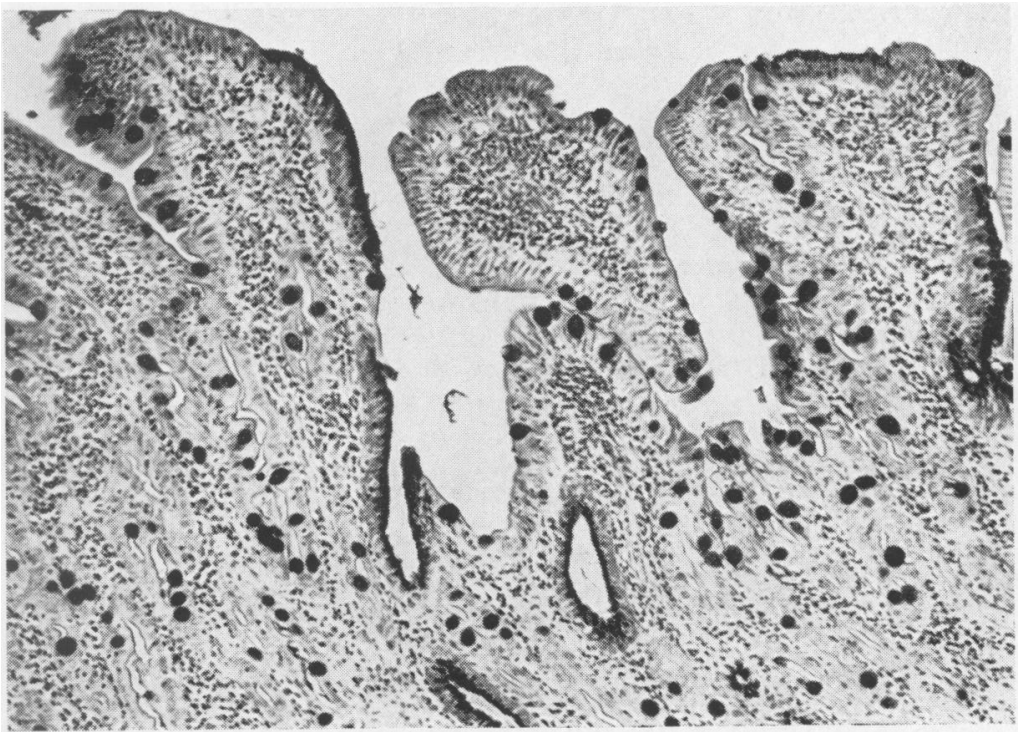

FIG. 1. Cat. 26 A normal villus in the duodenum. The left side and tip are covered with gastric epithelial cells. $($ P.A.S. $\times$ 300. $)$

FIG. 2. Cat 13. A stunted villus in the duodenum with gastric epithelial metaplasia on its left side. (P.A.S. $\times$ 400.)

FIG. 3. Cat 20. Two stunted villi with some gastric epithelial metaplasia on them. Deep to the surface are similar cells lining ducts. $($ P.A.S. $\times 120$.

FIG. 3 


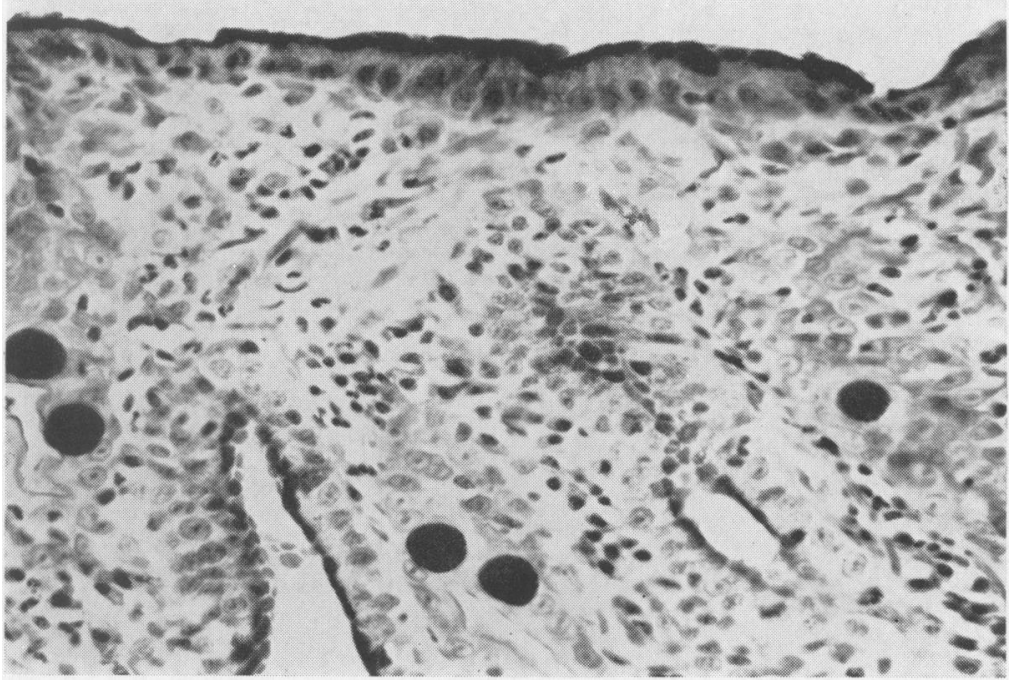

FIG. 4. Cat 20. A flat area in the duodenum without villi. The surface is covered with gastric epithelial cells which in this area are short with a small mucous droplet. (P.A.S. $\times$ 400.)

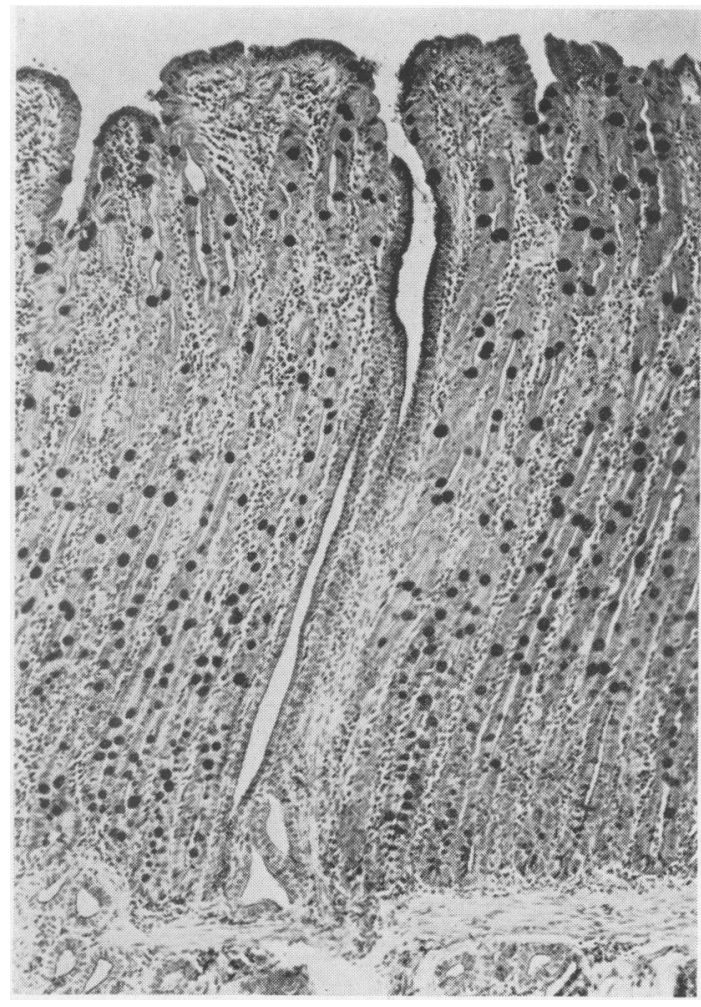

FIG. 5. Cat 20. A Brunner's gland duct extends from the muscularis mucosae to the surface. Cuboidal cells containing mucus line the superficial part of the duct and extend on to the surface. (P.A.S. $\times$ 30.)
Amongst the injected cats it was more common in those with microscopic mucosal ulceration (seven out of eight) than in those without ulceration (three out of eight).

The gastric epithelium was most often seen on stunted villi (Figs. 2 and 3) but occasionally on a normal villus (Fig. 1). The only control cat with any patches of superficial gastric epithelium in the duodenum was also the only control to have stunted villi. In areas where there were no villi and the mucosa was ulcerated, the epithelium between the ulcers was gastric in type (Fig. 4).

In both control and injected cats there were, among the cells lining the ducts of Brunner's glands, groups of cells similar to gastric epithelium. Many of the cells were cuboidal, rather than columnar, and contained only a small mucous droplet, but there was a gradual transition between such cells and cells typical of gastric epithelium on the surface with which they were sometimes continuous (Fig. 5). A patch of gastric type epithelium on the surface was often found in association with a deeper group (Fig. 3). Ninety-four superficial areas were counted and in 54 of them there was an associated deeper group.

JEJUNUM The upper jejunum beyond the end of Brunner's gland tissue was examined. Sometimes there was ulceration, sometimes villous shortening, but never gastric epithelium.

\section{DISCUSSION}

Gastric epithelial metaplasia in the duodenum of animals has been noticed by others. Florey and 
Harding in 1935 studied the histological changes following the excision of 1 square centimetre of mucosa from the first part of the duodenum of cats. After seven days a layer of cells indistinguishable from gastric epithelium had begun to grow across the defect. This epithelium persisted throughout the period of healing and was still present after 102 days in the form of small patches on the newly-formed villi.

Florey, Jennings, Jennings, and O'Connor (1939), while investigating the protective action of Brunner's glands in pigs, inserted a duodenal fistula between a Pavlov pouch and the jejunum. The segment of duodenum was presumably exposed to a high level of acidity. After nine months the duodenal villi had become distorted or flattened and many of them were covered with gastric epithelium.

Merkel (1941) studied the histological changes in the duodenal mucosa of small animals following histamine injections. He emphasized the vascular changes and noted the presence of areas of sloughing mucosa but did not refer to the epithelial changes described in this paper.

Distortion and shortening of villi has been produced in dogs by instilling small volumes of $\mathrm{N} \mathrm{HC1}$ into Thiry Vella loops of jejunum (Townley, Cass, and Anderson 1964). Serial biopsies showed that after several days the villi became stunted; they returned to their normal size when instillations of acid were stopped. The villous changes in the present investigation were similar and are assumed to be the direct result of a high duodenal acidity.

The findings in this paper resemble those in humans. Thus James (1964) noticed that gastric epithelium in the duodenum was most marked on the flattened villi of patients with duodenal ulcers who might therefore be expected to have had a high acid output.

The gastric epithelial cells in the duodenum probably originate in the necks of Brunner's glands. The evidence for this hypothesis is that the mucuscontaining cells could often be seen extending from the duct on to the mucosal surface. Those in the duct were cuboidal, but those on the surface columnar. Even when the contiguity could not be seen, $60 \%$ of the superficial patches were associated with a deeper group lining a duct. Gastric epithelium was never found on the surface of tissue below which there were no Brunner's glands; thus beyond the limits of the extent of Brunner's glands there might be superficial ulceration and stunting of the villi but there was never any gastric epithelium. In the gastric antrum surface epithelium arises from the pyloric glands (Creamer, Shorter, and Bamforth, 1961). It is not surprising that Brunner's glands, which closely resemble pyloric glands, should be capable of giving rise to gastric epithelium.

It is assumed that mucosal ulceration and villous shortening is the result of a high level of acidity in the duodenum. Gastric epithelial cells from the necks of Brunner's glands grow on to the surface. A persistently high level of duodenal acidity will cause the process to continue and maintain this surface layer.

\section{SUMMARY}

To see if exposure of the duodenal mucosa to increased amounts of acid from the stomach resulted in gastric epithelial metaplasia in the duodenum, cats were given daily injections of histamine in beeswax.

Gastric epithelium in the duodenum was rare in control cats but common in those injected with histamine. It was more common in injected cats which had duodenal ulceration and stunted villi.

The gastric epithelium probably arises from the necks of Brunner's glands.

I am indebted to Dr. A. H. James for suggesting that this work should be done and for helpful criticism, to Professor F. W. Landgrebe in whose department the experiments were carried out, to the staff of the Institute of Pathology who prepared the sections, and to Mr. R. Marshall for the photomicrographs. This work was carried out while holding the Cardiff Royal Infirmary Research Fellowship in Medicine.

\section{REFERENCES}

Creamer, B., Shorter, R. G., and Bamforth, J. (1961). The turnover and shedding of epithelial cells. Gut, 2, 110-116.

Florey, H. W., and Harding, H. E. (1935). The healing of artificial defects of the duodenal mucosa. J. Path. Bact., 40, 211-218.

—_, Jennings, M. A., Jennings, D. A., and O'Connor, R. C. (1939). The reactions of the intestine of the pig to gastric juice. Ibid., 49, $105-123$.

Hay, L. J., Varco, R. L., Code, C. F., and Wangensteen, O. H. (1942). The experimental production of gastric and duodenal ulcers in laboratory animals by the intramuscular injection of histamine in beeswax. Surg. Gynec. Obstet., 75, 170-182.

James, A. H. (1963). Gastric epithelium in the duodenum of a patient with gastric hyperacidity. Proc. 2nd Wld Congr. Gastroent., Munich, 1962, 2, 540-543.

(1964). Gastric epithelium in the duodenum. Gut, 5, 285-294.

Merkel, H. (1941). Uber experimentelle Erzeugung akuter und chronischer peptischer Magenschleimhaut: veränderungen durch Histamin. Beitr. path. Anat., 106, 223-262.

Townley, R. R. W., Cass, M. H., Anderson, C, M. (1964). Small intestinal mucosal patterns of coeliac disease and idiopathic steatorrhoea seen in other situations. Gut, 5, 51-55. 